\title{
Exploracão social e estrutura de classes: a atualidade de um quadro de análise
}

\section{Luiz Inácio Gaiger ${ }^{*}$ ()}

\section{Resumo}

O artigo aborda os conceitos de relações de exploração, classes e estrutura de classes, destacando a necessidade de considerar os distintos níveis internos desse arcabouço teórico para fins de análise das sociedades contemporâneas. Fundamenta-se em revisão bibliográfica das objeções levantadas à teoria das classes, bem como em uma retomada de elementos seminais legados por Karl Marx e de contribuições posteriores de intérpretes dos textos marxianos, com destaque a Eric Wright. Sustenta que a exploração social, da qual deriva uma dada estrutura de classes, é o ponto de partida para uma teoria das classes que supere o seu aparente anacronismo, seu presumido economicismo e seu suposto vínculo imanente com uma teleologia da transformação social. A abordagem das classes, assim concebida e integrada a um tratamento teórico sobre a formação de preferências e a mobilização coletiva, constitui um instrumento indispensável para a análise tanto da estrutura quanto da ação social.

Palavras-chave: exploração, classes sociais, estrutura de classes, marxismo, Erik Wright.

\footnotetext{
* Universidade do Vale do Rio dos Sinos, São Leopoldo, RS, Brasil.
} 


\section{Social exploitation and class structure: the topicality of an analytical framework}

\section{Abstract}

The article addresses the concepts of social exploitation, classes and class structure, highlighting the need to consider the different internal levels of this theoretical framework for the purpose of analyzing contemporary societies. This approach is based on a bibliographic review of the objections raised to class theory, as well as a resumption of seminal elements left by Karl Marx and later contributions by interpreters of Marxian texts, such as Eric Wright. From this standpoint, it is argued that social exploitation, from which a given class structure derives, is the starting point for a class theory that overcomes its apparent anachronism, its presumed economism and its supposed immanent link with a teleology of social transformation. The social classes approach, thus conceived and integrated with a theory on the formation of preferences and collective mobilization, constitutes a valuable tool for examining both social structure and social action.

Keywords: exploitation, social classes, social structure, Marxism, Erik Wright.

\section{Introdução}

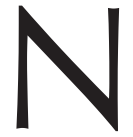

as últimas décadas, o conceito de classe social não manteve a mesma relevância que tivera até meados dos anos 1980 na análise da estrutura social e dos comportamentos coletivos. Embora siga usual em estudos de estratificação social, ele passou a ser utilizado como elemento causal em quadros analíticos mais restritos, em contraste com seu papel outrora explicativo de questões mais gerais, ou mesmo centrais. Da mesma forma, a ideia de totalidades, de cuja estrutura intrínseca derivava o caráter determinante de certas relações sociais, especialmente de classe, caiu em desuso. A classe não desapareceu do horizonte, como exemplificam estudos empíricos inspirados em Bourdieu (Bertoncelo, 2016) e reconstruções de abordagens de referência, em particular no âmbito do marxismo (Viana, 2018). Contudo, em geral, deixou-se de lado o status de categoria explicativa primordial antes atribuído à classe e, com isso, as 
teorias conexas, ou seja, elementos fundacionais de uma visão tanto da estrutura quanto da ação social. Esse afastamento das classes trouxe consigo uma relativização acentuada da determinação exercida pela infraestrutura material na conformação de interesses, na constituição de grupos sociais, na emergência de conflitos e no advento de formas de solidariedade. Isto, a ponto de se incorrer no risco de supressão ou diluição do econômico na análise sociológica, como já se advertiu há vários anos (Guimarães, 1993).

Entretanto, a extração dos excedentes do trabalho desde o terreno da produção e da distribuição da riqueza não se tem arrefecido, mantendo viva a ideia de que as demandas sociais, mesmo se como tais alheias à esfera econômica, permanecem marcadas por sua conotação classista. Isto, numa época em que a dinâmica capitalista, havendo já há tempos ingressado na era da acumulação flexível (Harvey, 1992), recuperou antigas formas de exploração da força de trabalho, cujo caráter classista não daria motivos à dúvida. Como destacam autores de referência (Therborn, 2011), as classes sociais retornaram à cena das desigualdades e dos conflitos sociais. Em nossos dias, o fato mais emblemático a esse respeito talvez seja o impacto social diferenciado das políticas neoliberais, tanto quanto as reações contra elas, do âmbito de questões trabalhistas àquelas atinentes a modelos de desenvolvimento (Boito Jr.; Berringer, 2013) ou envolvendo recursos naturais e comunidades (Sassen, 2014). Não sem razão, o número de abril de 2019 de Global Dialogue, publicação da Associação Internacional de Sociologia, traz um dossiê sobre "Novas direções para uma sociologia global" com artigos sobre classes e desigualdades. Da Alemanha à América Latina e à China, todos eles enfatizam a relevância dos estudos de classe, indicam questões relacionadas à formação e às relações de classe e convidam-nos a criar ou tomar parte em redes internacionais de pesquisa sobre esses temas.

O primeiro objetivo deste artigo consiste em retomar algumas objeções feitas ao foco nas classes, evidenciando alguns meios para transpô-las. Em linhas gerais, elas incidiram em três pontos: quanto ao anacronismo do conceito (a sociedade modificou-se e retirou a centralidade ou a relevância dos processos formadores das classes como determinantes da dinâmica 
social); quanto a seu pendor reducionista, que as prende à esfera econômica (ocultando ou desprezando dimensões extraeconômicas ou imateriais que igualmente influenciam a vida coletiva); e quanto à sua teleologia imanente (a ação das classes como vetor central da transformação histórica em direção a uma sociedade superior, não classista). Tais problemas não deveriam ser tomados em bloco, pois referem-se a planos factuais e teóricos distintos, embora inter-relacionados. Esclarecendo, refinando e completando os fundamentos teórico-analíticos que cercam a questão das classes desde a obra de Marx, é possível evitar uma relação causal simplificada entre a esfera da produção e a superestrutura política e ideológica, bem como ampliar a problemática da constituição dos sujeitos, integrando outras motivações aos interesses advindos da exploração econômica.

Nesse sentido, o segundo propósito deste artigo reside em evidenciar que há ganhos analíticos em retomar as formulações seminais de Marx à luz de autores neomarxistas, em particular Eric Wright. Nesse prisma, o conceito de classes encontra-se umbilicalmente ligado à desigualdade e à exploração: seu cerne reside na presença de um mecanismo de expropriação da riqueza, ocasionando sua transferência unilateral ou desigual de uns para outros. Essas relações engendram um quadro de interdependência conflitiva e potencialmente explosiva, cuja resultante é a coexistência de grupos sociais antagônicos - as classes.

De mais a mais, nem todas as divisões e desigualdades sociais são classistas. A importância das classes sempre dependerá da relevância que se atribuir às relações sociais de exploração: se há clivagens sociais instituídas por e instituintes de relações de exploração, uma análise de classes bem construída torna-se fundamental. Isso implica distinguir linhas divisórias fundamentais, que cindem a sociedade em grandes campos opostos, de outras linhas subordinadas às primeiras, que fracionam os grupos sociais ou acrescentam figuras adjacentes, típicas de uma nova totalidade social ou remanescentes da sociedade anterior, uns e outros secundários do ponto de vista teórico da contraposição central entre exploradores e explorados. Esse gradiente, cuja exposição constitui o terceiro propósito do artigo, conforma 
uma estrutura de classes (Wright, 2015), analisável em diferentes níveis e âmbitos, de acordo com a coexistência e a imbricação entre modos de produção e formas sociais de produção (Gaiger, 2003). Expansível, esse dispositivo analítico permite transitar da polarização basilar entre explorados e exploradores às demais classes e frações de classe que se constituem em cada estágio de desenvolvimento de uma dada formação social.

Seguindo essa linha condutora, na qual o conceito de classe é integrado a uma teoria sobre a exploração e a estrutura de classe, tenciona-se demonstrar a pertinência e, assim sendo, a validade atual de uma abordagem classista das sociedades. Embora as objeções às análises focadas em classes sejam parcialmente refutadas na primeira seção, infra, novos elementos serão progressivamente acrescentados ao longo das seções seguintes, seja por meio de argumentos teóricos ou de exemplificações da aplicabilidade do arcabouço proposto. O que se tenciona, portanto, não é extrair argumentos em favor da atualidade das classes de um balanço abrangente da literatura a respeito, sabidamente vasta e diversa, mas sim por meio da proposição de um constructo teórico-conceitual cujo ponto de partida é Marx e cujas contribuições mais recentes provêm de diversos autores, não exclusivamente do campo marxista.

\section{Análise das objeções ao foco em classes sociais}

Em um compêndio de sociologia lançado ao final dos anos 1980 (Durand-Sebag, 1989), um verbete dedicado a "classes sociais" pontuava uma dúvida então persistente na literatura: o conceito de classes sociais seria empírico e descritivo, o que garantiria às classes uma existência real, ou dito conceito seria de natureza teórica, referindo-se a um conjunto abstrato de relações não aparentes, que tanto estruturam o sistema social quanto apontam mecanismos subjacentes à ação dos grupos sociais e às transformações na sociedade? Embora os autores partidários do segundo enfoque jamais tenham abdicado da força teórica do conceito, parece terem sido os fatos concretos - o visível declínio da capacidade efetiva de 
ação das classes sociais existentes naquele momento histórico da Europa o que provocou hesitações e acarretou um descrédito gradativo quanto às propriedades explicativas e politicamente relevantes do conceito de classes.

Até então, os acalorados debates teóricos e a profusão de estudos sobre as classes haviam coincidido com um movimento operário consideravelmente ativo e potente no mundo industrial. Mas o cenário estava mudando, com o inegável refluxo do movimento operário, representante por excelência da classe trabalhadora (Durand-Sebag, 1989, p. 258). Seria isso uma consequência das amargas derrotas diante da inflexibilidade dos governos neoliberais? Ou algo imputável à crescente complexidade da estrutura social, em particular devido à emergência de uma nova classe média, desprovida de ideologia e de projeto de sociedade? Um exemplo convincente foi trazido, no mesmo verbete, pelo diagnóstico do sociólogo Wright Mills sobre o que sucedia na sociedade estadunidense desde o início dos anos 1950, com o ascenso do pequeno burguês incarnado pelos colarinhos brancos, que "não possuem nem a força nem a vontade de se engajar em uma luta política" (Wright Mills, 1970, p. 15, apud Durand-Sebag, 1989, p. 258). ${ }^{1}$

O fato é que aquele cenário de dúvidas e questionamentos sobre o poder explicativo das classes refletiu-se na sociologia brasileira, embora naqueles mesmos idos de 1980 não tenha havido no Brasil um arrefecimento do movimento sindical e das lutas operárias. Ademais, verificava-se uma profusão de novas e crescentes mobilizações originadas da esfera da reprodução (como se dizia na época), como as lutas contra a carestia, por moradia e transporte coletivo (Doimo, 1995), ou assumindo contornos irredutíveis à esfera econômica, como direitos humanos, questões indígenas e demandas relacionadas ao meio-ambiente. Enfim, uma plêiade de causas e mobilizações (Scherer-Warren; Krischke, 1987) que desaguaram nas frentes populares pró-constituintes. Com tantos novos atores entrando em cena (Sader, 1988), as classes sociais deveriam sair?

\footnotetext{
1 Trata-se de uma obra clássica de Charles Wright Mills - White collar: the American middle classes, Oxford University Press, 1951 - citada em sua versão em francês, de 1970, e traduzida por nós, a exemplo de outras citações de fontes em língua estrangeira ao longo do artigo.
} 
Uma das raízes dessa crise conceitual situa-se na forma como se desenvolvera a abordagem marxista predominante a respeito, até sofrer abalos no correr dos anos 1970: um tratamento concebido nos termos da ortodoxia prevalecente até meados do séc. XX, segundo a qual as classes seriam axiomaticamente dedutíveis do desenvolvimento capitalista e da inescapável contradição entre o capital e o trabalho. Sendo assim, as atenções concentravam-se na esfera da produção ou do trabalho produtivo, lócus de análise da evolução esperada dos grupos sociais para cumprirem o seu desiderato de classe, não obstante o persistente comportamento contrafactual de tais grupos em relação a essa mesma teoria e à sua carga apologética. Em consequência, práticas sociais diferenciadas, por conta inclusive das distintas inserções dos segmentos populares no quadro da exploração capitalista, "foram banidas do mundo da 'verdadeira' classe social" (Sader; Paoli, 1986, p. 46-7).

Um posicionamento comum entre os críticos das classes foi a rejeição aos enfoques monocausais deterministas, em nome da multidimensionalidade dos processos de constituição das preferências, identidades e formas de atuação (Guimarães, 1993, p. 85). Diante da trepidante remobilização social da época, os atributos de incompletude da formação classista, de alienação e de subalternidade moral que antes explicavam o escasso pendor revolucionário do ator popular, deram lugar a novas inflexões analíticas e a renovações na agenda de pesquisa. Balanços amplos da literatura, como em Sader e Paoli (1986), e estudos empíricos atentos, como em Oliveira (1987), reconstruindo comedidamente as articulações entre teoria e empiria, conduziram à suspensão (ou suspeição) das categorias pré-constituídas e terminativas, de sorte que a formação de sujeitos políticos de classe passou a figurar como um tema, entre outros, da agenda de estudos, aproximando-a dos processos socioculturais de subjetivação e de representação social. Na década de 1990, a análise dos condicionantes subjetivos da ação de classe ganhou terreno, ensejando uma farta literatura sobre a cultura operária e popular. Os enfoques se diversificaram, incorporando novas categorias como identidade, cidadania, cotidiano e experiência. Tais conceitos denotavam uma 
“preocupação em tratar os dominados como criadores dos seus próprios mundos, comprometendo a análise com a emergência da consciência de direitos, individuais e coletivos, por parte não apenas dos operários, mas das camadas populares" (Guimarães, 1999, p. 25).

As classes teriam ainda assim permanecido à tona, não fosse uma preferência disparada das teorias emergentes por novas categorias, em particular a de movimentos sociais, aos quais se terminou concedendo por vezes um estatuto teórico similar ao das classes (Guimarães, 1999, p. 25-27). O "conceito de classe foi praticamente abandonado pela Sociologia brasileira, sem que, no entanto, se enfrentasse, como se tem verificado em nível internacional, a questão em termos propriamente teóricos" (Guimarães, 1993, p. 85). ${ }^{2}$

Mais do que refletir a realidade nacional, a perda de relevância das classes sociais no Brasil estava em compasso com novas tendências da literatura internacional, não obstante as desigualdades e os conflitos sociais outrora associados às propriedades explicativas do conceito de classe tenham recrudescido nos últimos 25 anos. As mutações das sociedades do Norte, às vezes transpostas ao Sul sem a devida recontextualização, induziram essas mudanças de perspectiva. Sejam elas, considerando a perda de centralidade da esfera da produção e do trabalho, compensadas pelas esferas de circulação da informação e de consumo como princípios organizadores da sociedade e ordenadores das preferências e afiliações; sejam como um reflexo da fragmentação social e da indeterminação e pulverização dos vínculos e condutas, o que retiraria da esfera econômica como de qualquer outra - a função primordial de prover suporte ideológico e configurar os agentes políticos Para alguns, "no contexto da transição para a sociedade pós-industrial, novas clivagens sociais (em torno de padrões de consumo, etnia, gênero etc.) tenderiam a emergir e a conformar mais fortemente identidades coletivas e preferências políticas" (Bertoncelo,

2 Ambos os trabalhos citados nesse parágrafo - de autores distintos, apesar da homonímia - são referenciais a esse respeito. O primeiro, ao historiar o tratamento dados as classes pela sociologia brasileira no último quartel do séc. XX; o segundo, ao sintetizar em poucas páginas as principais questões e teses envolvidas. 
2009, p. 37). Para outros, a transição pós-moderna é que estava em causa, incrementando a reflexividade e ensejando uma "ampliação do leque de escolhas em torno dos estilos de vida e do planejamento da vida", em inegável detrimento das determinações de classe (Bertoncelo, 2009, p. 38).

Nesse novo estágio do capitalismo, restariam apenas indivíduos autotélicos, de escassa vocação cívica e de postura blasé diante dos assuntos públicos, referendando o prognóstico sombrio de Wright Mills? Ou seria imprudente abstrair o domínio do capital com sua lógica de acumulação, hoje de vento em popa em escala global, e os seus efeitos incontroláveis sobre a distribuição de recursos entre indivíduos, grupos e nações? Afinal, rentista e especulativo em suas configurações mais lucrativas e sedutoras, o capitalismo jamais produziu tanto e redefiniu tão velozmente a sorte de contingentes humanos inteiros, ao afetar territórios, bens comuns e expectativas de bem-estar (Dowbor, 2017).

Tais efeitos se fazem sentir também sutilmente, em planos menos visíveis. Estudos sobre classe, organização familiar, educação e raça demonstram a preponderância do nível econômico, acoplado a um estilo de vida, sobre outros fatores de diferenciação entre famílias, o que afeta seus ciclos e aspirações (Lareau, 2007). A tendência em atribuir menor importância às divisões sociais, em particular classistas, na explicação do comportamento eleitoral em democracias avançadas, tem sido contrastada por pesquisas internacionais que revalorizam a classe social como fonte de orientação do voto (Ferraz, 2009). Examinando novas tendências e configurações mundiais das desigualdades, Therborn (2011) concluiu pelo retorno da classe como propulsor das crescentes disparidades de renda e de bem-estar, enquanto a pressão de fatores socioculturais como o racismo e o sexismo estariam em refluxo, graças aos avanços havidos nesses campos. Se a classe operária da Europa e da América do Norte encontra-se hoje "dividida, derrotada e desmoralizada", a classe trabalhadora industrial ressurge na China, podendo ocasionar "um novo round de conflitos distributivos". Outro cenário derivaria "das classes populares heterogêneas da África, Ásia, América Latina e, talvez, de seus correspondentes menos vigorosos do 
mundo rico", que enfrentam obstáculos severos, mas não intransponíveis, à sua organização e mobilização (Therborn, 2011, p. 5).

Por conseguinte, as classes não se manteriam como elementos subjacentes às afinidades, condutas e solidariedades não-classistas, definindo em certa medida seus contornos? Nas atuais condições, elas não exerceriam um papel preponderante sobre o uso do tempo, o cultivo dos gostos e os estilos de consumo, como frisava Bourdieu (1996)? Naturalmente, admitir algum grau significativo de influência da esfera econômica na conformação dos grupos sociais e na estruturação de suas predisposições não implica postular sua exclusividade, nem sequer sua preponderância como regra geral. Ademais, já não é sustentável que a passagem da classe à ação coletiva seja automática. Embora não seja, nos dias atuais, completa verdade (Silveira; Doray, 1989), a ausência de uma teoria da subjetividade conduziu o marxismo clássico a negligenciar a influência exercida por fatores não econômicos, o fato de a vida social apoiar-se em componentes normativos decisivos para a criação e o cultivo de elos de solidariedade moral que unem os membros da classe (Bertoncelo, 2009, p. 33). A expectativa de um avanço progressivo natural na conformação objetiva e subjetiva das classes desviou a atenção dos fatores de divisão e enfraquecimento das classes exploradas, decorrentes da posição ambivalente que ocupam diante das lógicas instituídas, o que torna ambíguas suas reações, travando-as e desmobilizando-as. Por fim, frente à privação ou a aspirações insatisfeitas, deve-se admitir várias reações possíveis, não apenas o mero conformismo ou a flamante revolta, sendo ademais implausível que tais reações conduzam em regra a formas de ação organizada.

Se Marx, em pessoa, demonstrou suas reservas às inclinações economicistas das lutas operárias, foi talvez por ter pressentido que a resignação e o pragmatismo tendem a prevalecer em situações normais de assimetria de poder, abrindo-se com isso outras vias entre a simples subordinação e o caminho antagônico da insurreição. Essa atitude de consentimento da classe operária, contudo, não decorreria de uma falta de consciência (de classe), e sim de um ajuste racional entre meios e fins 
realistas, como sustentam próceres do marxismo analítico (Przeworski, 1977). De mais a mais, o primado materialista que conduziu à supremacia in totum da esfera da produção econômica, sua articulação direta com a esfera da cultura (a ideologia classista) e a política (a luta de classes), tanto como a elevação do proletariado à primazia de sujeito histórico - elementos que deram esteio à visão marxista da transformação histórica - já foram objeto de refutações abalizadas; entre elas, quanto à missão imanente à classe trabalhadora de conduzir-nos todos à inexorável revolução socialista (Gorender, 1999). Embora tenham motivado intensas controvérsias, esses elementos teleológicos são dissociáveis dos fundamentos teórico-analíticos que cercam a questão das classes na obra de Marx.

Conviria, por outro lado, ter em vista alguns limites e riscos implicados em abordagens da ação coletiva que se demarcaram das classes, especialmente aquelas referenciadas nos "novos movimentos sociais". Em primeiro lugar, tal distanciamento justificou-se como meio de superar a dicotomia entre estrutura (classes) e agência (movimentos), supostamente inerente à análise de classes. Uma alegação discutível, uma vez que os estudos de classe, sobretudo no caso dos trabalhadores ou das classes populares, também tiveram em vista suas possibilidades de ação, e não apenas sua posição estrutural. A supervalorização de outros condicionantes das condutas coletivas pode induzir ao abandono das preocupações com as condições econômicas, levando-as a figurar apenas como um dado contextual de fundo, inorgânico, de sorte que as propriedades de classe deixam de comparecer na explicação. Mesmo a hipótese de cumprirem um papel secundário não deveria justificar sua dispensa, pois fatores dessa ordem também são relevantes. Dever-se-ia trabalhar integrando enfoques, dados seu relativismo intrínseco e os benefícios prováveis de considerar zonas de intersecção entre teorias como tais independentes.

De outra parte, a adesão a perspectivas teóricas se faz, por vezes, sem a transferência refletida do seu contexto original para aquele de sua pretendida aplicação. Categorias como pós-modernidade e sociedade pós-industrial não deveriam ser transpostas sem maiores considerações 
e ajustes às sociedades do Sul. A questão é relevante, pois predetermina os pontos de partida e de chegada, com riscos de reproduzir os vícios da razão metonímica e indolente, como adverte Santos (2002). A indistinção entre a parte e o todo pode ainda expor-nos, em outra seara, a um elitismo involuntário, do qual não escaparam análises classistas da ação coletiva: embora congregue um certo número de indivíduos, a ação coletiva via de regra é obra de minorias que se organizam, mobilizam e reivindicam em nome de uma população maior, enquanto essa reage esporadicamente, permanecendo em geral apática. Manifestações de massa contínuas e sistemáticas são raras. Onde estão as maiorias? À análise das minorias ativas (Moscovici, 2011), conviria acrescentar uma teoria da dinâmica das mobilizações sociais.

\section{O ponto de partida marxiano}

Outra questão de fundo, que perpassa controvérsias internas às teorias classistas e boa parte dos argumentos que as rejeitam, tem a ver com a indistinção entre os níveis de abordagem da realidade empírica a partir do conceito de classe, que corresponde (ou pode corresponder) a graus de abstração e abrangência variados. Aqui, há margem para vários esclarecimentos, o que justifica retomar o assunto desde seu princípio, em Marx. De imediato, notemos que o conceito de classe não deve ser hipostasiado: ele não se refere a uma realidade alante, mas registra a condição relacional de um conjunto de agentes cujas afinidades provêm de sua inserção similar na esfera econômica, de acordo com a estrutura de propriedade e com a divisão social do trabalho. Como veremos, uma classe pode existir no plano mental, desde que encontre lugar em uma dada estrutura de classes (Wright, 2015), sem que exista ela própria (ou tenha um correspondente empírico) em todas as circunstâncias históricas em que dita estrutura é útil como instrumento heurístico e explanatório.

Voltemos a Marx: embora o conceito de classe social tenha importância capital em seu pensamento, ele não se deteve em um estudo demográfico 
ou em uma caracterização precisa das classes sociais, enquanto discorria sobre elas. À época, as classes designavam uma realidade clara para o senso comum, associada às novidades que suplantavam o Antigo Regime e abriam portas à ascensão de novos grupos sociais, já não mais por graça de direitos herdados ou adquiridos sem trabalho, mas em virtude de suas iniciativas e sua labuta, especialmente no campo econômico. Era desejável estar em uma classe e ter classe. Marx tratou de questionar essas evidências e, assim, produziu uma teoria crítica sobre as forças motrizes do ordenamento social, transformando uma noção comum em objeto científico.

Os primórdios do capitalismo na Inglaterra, a emergência do proletariado e as lutas sociais nesse tipo de sociedade constituíram também o ponto de partida da teoria marxista da história. Contudo, Marx desenvolveu o corpo de ideias que viriam a formar o materialismo histórico e dialético - ou a Filosofia da Práxis, como anunciou com Friedrich Engels na Ideologia Alemã - com o propósito de elucidar as causas estruturais das desigualdades e desvelar o funcionamento daquilo que lhe parecia indubitavelmente constituir relações sociais de dominação e opressão. Concluiu que as diferenças sociais, nem sempre aparentes, não se deviam a fatores meramente circunstanciais, a virtudes pessoais ou a causas fortuitas, do contrário não seriam recorrentes e persistentes; tampouco alguns indivíduos usufruiriam de tanto poder, ao lado de outros condenados à subalternidade. Era preciso que a riqueza, advinda do trabalho da maioria, fosse drenada e transferida para uma minoria por um mecanismo impositivo de extração e acumulação. ${ }^{3}$

Assim, o conceito de classes está umbilicalmente ligado à desigualdade e à dominação, a lógicas de expropriação e de poder: as classes são seu reflexo e, reproduzindo-se, asseguram sua continuidade. O cerne da questão reside na presença de um mecanismo irrefreável de expropriação da riqueza produzida no presente (ou já anteriormente) pelo trabalho, ocasionando sua transferência unilateral ou desigual de uns para outros. Trata-se de uma relação peculiar, de exploração, pela qual a classe exploradora se alimenta

3 Para uma síntese do próprio Marx, é útil consultar o cap. XLVIII (A fórmula trinitária) de $O$ Capital (Marx, 1968-1974). 
da atividade produtiva da classe explorada, necessitando para isso dos seus esforços e, tanto quanto possível, de seu consentimento.

Conforme Wright (2015, p. 132-134), a exploração implica um padrão estruturado de relações, uma situação de interdependência conflitiva e potencialmente explosiva. Não consiste propriamente na exclusão ou na opressão de um grupo por outro, quando então o primeiro deles é dispensável e pode ser descartado, como já se viu em tantas tragédias humanas de emigração forçada ou de genocídio e volta-se a ver por força da economia globalizada (Sassen, 2014). Os senhores de engenho precisavam dos seus escravos, como os fazendeiros de seus peões e os capitalistas de seus trabalhadores assalariados: o bem-estar dos primeiros depende causalmente do esforço dos segundos, não apenas das suas privações (Wright, 2015, p. 133).

Uma vez desvelado esse mecanismo na economia capitalista, que para Marx estava assente na apropriação do excedente do trabalho via extração da mais-valia, não lhe restaram dúvidas de que algo análogo sucederia em outros sistemas econômicos: mecanismos latentes permitiriam a certos grupos sociais apropriarem-se do valor produzido pelo trabalho de outros, tanto dos vivos quanto de seus ascendentes; graças a isso, tais grupos privilegiados poderiam viver sem depender do seu próprio trabalho na mesma proporção do seu bem-estar. Esse mecanismo de exploração varia historicamente, mas incorpora um processo de expropriação posto em marcha pela divisão social do trabalho, lastreado no regime de propriedade e no acesso diferencial de uns e outros aos meios de produção. O objetivo de Marx era elucidá-lo, posto que de sua eliminação dependia o fim das desigualdades e, virtualmente, o desaparecimento das próprias classes. ${ }^{4}$

Negar a existência ou a relevância das classes equivaleria a refutar ou negligenciar a existência de instituições como a escravidão e a servidão. Por isso, a preocupação central de Marx não foi delimitar as classes com base

${ }^{4}$ Assim, embora a análise de Marx não se tenha fundamentado em categorias morais, as questões da justiça social e da distribuição da riqueza, assim como do poder e do controle social, compõem o seu pano de fundo e introduzem uma dimensão político-ideológica indissociável do conceito de classes sociais (Durand-Sebag, 1990, p. 268). 
em algum princípio de estratificação, mas identificar o princípio estrutural de diferenciação e contraposição em relação ao qual os grupos sociais reais deveriam ser posicionados, a despeito de suas eventuais similitudes aparentes ou mesmo de preferências comuns manifestas. ${ }^{5}$ A consequência inevitável desse dispositivo é a formação de grupos sociais antagônicos, designados de classes como referência genérica aos produtores diretos e aos proprietários ou controladores das condições de produção, cuja relação constituía "o segredo mais íntimo, o fundamento oculto, de todo o edifício social". ${ }^{6}$ Em cada tipo de sociedade - ou em cada modo de produção haveria uma síntese específica das múltiplas determinações que conformam e asseguram o mecanismo de expropriação e de reprodução das classes, para o qual sempre concorrem, em última instância, as práticas assentes no acesso aos meios de produção e na divisão social do trabalho.

Isso posto, seria razoável imaginar que a condição de classe de grupos e indivíduos - o fato de estarem na condição de expropriadores ou de expropriados - não afete sua visão de mundo, seus interesses mais retilíneos e, assim, seus comportamentos? Ou surpreendente seria que sua visão de mundo e suas condutas se assemelhassem? As concessões podem ser mútuas, mas terão efeitos opostos para cada um dos lados e, provavelmente, sentidos diferentes. A situação de classe gera interesses específicos de classe, diante dos quais as ações e estratégias dos grupos sociais correspondentes são habitualmente avaliadas tanto por estudiosos quanto pelos próprios agentes implicados. O interesse de classe funciona aqui como um elemento balizador, a indicar que o lado da mesa em que se está, quando se negociam as condições de exploração, faz diferença sobre o que interessa e, portanto, sobre o que provavelmente se pensa a respeito, ainda quando as ações não chegam a deixar que tais entendimentos transpareçam.

5 Por isso, provavelmente, encontramos dele apenas um esboço do que seria uma caracterização das classes sociais no capitalismo, escrito no apagar das luzes da redação incompleta de O Capital (Capítulo LII - o último escrito por ele próprio e não por Engels). As bases do projeto investigativo em questão haviam sido anunciadas vários anos antes, na Ideologia Alemã (Marx; Engels, 1984).

${ }^{6}$ Citado por Bottomore (1988, p. 62), de O Capital, III, cap. XLVIII. 
Apesar de termos aqui um princípio simples em sua formulação elementar, ele tem sido causa de mal-entendidos e controvérsias. O que se pode depreender a respeito, nos textos de Marx, é o princípio lógico acima exposto: ao corresponderem a um modo de inserção específica na esfera econômica, mais precisamente nas relações sociais de produção, as classes sociais descortinam uma perspectiva singular de ação para seus integrantes, uma situação objetiva a partir da qual suas condutas se materializam e são interpretáveis. Fatos impactantes afetam ditos integrantes de forma específica e devem refletir-se em suas preferências, ainda que eles não possam satisfazê-las a contento e precisem ajustá-las de acordo com suas escalas de preferências. Dizendo de outro modo, interesses manifestos ganham significado - do ponto de vista da análise, frise-se - a partir dos interesses objetivos de classe e dos antagonismos entre as classes que se estabelecem à medida que as mesmas formam uma unidade contraditória determinada pela vigência de relações de exploração. Classes e interesses de classe, assim, constituem categorias mentais que lastreiam a perspectiva geral e as hipóteses em análise, servindo de instrumentos para o investigador.

\section{Estrutura de classes e níveis teórico-analíticos}

No contexto do capitalismo em formação durante o séc. XIX, não havia dúvida de que o proletariado e a burguesia correspondiam a classes distintas, palpáveis, cuja existência saltava aos olhos. Marx destinou-lhes um grande papel no futuro, ao qualificá-las como as grandes classes da sociedade moderna, acrescentando aos assalariados e capitalistas também os proprietários de terras. Não obstante, admitiu que mesmo na Inglaterra, país em que o desenvolvimento daquela estrutura econômica era mais nítido, “não se patenteia pura essa divisão de classes. Também lá, as camadas médias e intermediárias obscurecem por toda a parte as linhas divisórias (embora muito menos nas zonas rurais que nas urbanas)" (Marx, 1974, p. 1012).

Ou seja, existem linhas divisórias fundamentais que cindem a sociedade em dois campos opostos, além de outras linhas subordinadas às primeiras, 
que fracionam os grupos sociais ou acrescentam figuras adjacentes, típicas da nova totalidade social ou remanescentes da sociedade anterior; uns e outros, secundários do ponto de vista teórico da contraposição central entre exploradores e explorados, própria do modo de produção em exame. A particularidade da burguesia e do proletariado é que: a) eram incarnados por classes empíricas com características distintivas visíveis, passíveis de aferição; b) ao contrário do campesinato, que numericamente constituía a maior classe no séc. XIX, a burguesia e o proletariado nascentes expressavam, em sua relação contraditória, o cerne do novo mecanismo de exploração que se instaurava por meio de relações sociais assalariadas de produção, conformando uma nova forma social de produção; c) essa nova forma constituía a base peculiar e o motor próprio do novo modo de produção capitalista, que se valeria ainda de outros instrumentos para garantir a reprodução e a ampliação do capital. Para o entendimento dessas nuances, é necessário então distinguirmos modo de produção e forma social de produção, além de aclararmos o conceito nodal de relações sociais de produção. Isto conduzirá ao conceito de estrutura de classes.

O modo de produção é a categoria mais fundamental e englobante cunhada por Marx para expressar sinteticamente as principais determinações que configuram as diferentes formações históricas. O conceito diz respeito à totalidade histórica, ao conjunto de relações que vinculam os indivíduos ao processo de produção, no sentido amplo de suas condições materiais de existência, compreendendo igualmente a circulação e a troca de bens materiais (Godelier, 1981, p. 174-175). Essas determinações encontram-se no modo como os indivíduos organizamse no que tange à produção, à distribuição e ao consumo dos bens necessários à sua subsistência; mais precisamente, na forma que assumem as relações sociais de produção, em conformidade com um dado grau de domínio das forças produtivas. O modo de produção representa a forma estruturante de cada sociedade, pela qual são providas suas necessidades materiais em dado estágio do seu desenvolvimento. 
Embora o modo de produção seja "uma totalidade orgânica e um processo reiterado de produção, distribuição, circulação e consumo de bens materiais, todas elas fases distintas e, ao mesmo tempo, interpenetradas no fluir de um processo único (...), é à produção que pertencem a determinação fundamental e o ponto recorrente" (Gorender, 1978, p. 23, grifo nosso). Em seu cerne, o modo de produção comporta um mecanismo social específico de criação, controle e apropriação do excedente social gerado pelo trabalho, o que lhe confere lógica e traços próprios imanentes à sua reprodução e ao padrão dinâmico de sua evolução histórica (Shanin, 1980, p. 61). Esse mecanismo é definido pelas relações sociais de produção, conforme três critérios: a) o tipo de acesso e controle dos indivíduos sobre os meios de produção; b) o papel que desempenham no processo de trabalho; c) os benefícios que auferem na distribuição do produto social. Quando envolvem a exclusão sistemática de alguns indivíduos do acesso aos meios de produção, pela força física ou pelo direito de propriedade (critério a), quando envolvem a apropriação dos frutos do trabalho dos excluídos por parte daqueles que controlam os recursos produtivos (critério $c$ ) e quando disso resultar que o bem-estar material desses últimos dependa do esforço laboral ou ainda das carências materiais dos primeiros (critério b), estaremos diante de relações sociais de exploração, no sentido já discutido (Wright, 2015, p. 133). Por esse motivo, as posições implicadas nessa relação contraditória e antagônica correspondem ao conceito de classes, em seu sentido mais abstrato, menos tangível e, no entanto, teoricamente mais relevante.

O modo de produção capitalista está lastreado em uma relação assimétrica entre indivíduos desigualmente posicionados face aos meios de produção e às condições de posta em valor de sua capacidade de trabalho, opondo os proprietários dos meios de produção aos assalariados. ${ }^{7}$ Uma relação classista, que se efetua, "através de uma colaboração ilusória, mas

7 Entende-se aqui o salário restritamente, no sentido da contrapartida ao trabalhador pela venda da sua força de trabalho ao capital. Hoje o termo é usualmente utilizado (e juridicamente instituído) para a maior parte das relações de emprego, incluindo trabalhadores domésticos e funcionários públicos, que também recebem um salário, mas cujo trabalho não é contratado pelo capital. 
não menos real, das três classes básicas, os assalariados, os capitalistas e os proprietários fundiários, na qualidade de donos dos fatores responsáveis pelos custos da produção de mercadorias" (Giannotti, 1976, p. 164). Reencontramos as três classes enunciadas por Marx em O Capital, sendo perceptível agora que ele se referia às duas classes teoricamente fundamentais e típicas do modo de produção capitalista e, também, ao fato histórico de que a classe exploradora se compunha, naquele contexto, de duas classes reais que viriam a fundir-se (e confundir-se) com a progressiva "conversão de toda propriedade fundiária à forma adequada ao modo capitalista de produção" (Marx, 1974, p. 1013).

Contudo, o uso do termo "modo de produção" por Marx não é unívoco. Isso ocasionou apreensões diferenciadas, tipologias complementares (modos de produção secundários, periféricos etc.) e tipos incompletos, como o modo de produção simples, em que o trabalhador possui os meios de produção e os coloca em movimento em diminutas unidades de produção. Tomando por base a exegese dos autores antes citados, tais entendimentos ficariam sem guarida, mas seria necessário reconhecer ao menos uma segunda acepção, na qual o termo modo de produção possui um caráter descritivo, referindo-se a uma certa forma concreta de produzir (artesanato, manufatura) ou, mais amplamente, a um estágio geral de desenvolvimento tecnológico (grande indústria, maquinismo).

Marx, nesse caso, refere-se a um modo material de produção: "os elementos e as formas materiais dos diversos processos de trabalho, pelos quais os membros de uma sociedade agem sobre a natureza que os cerca para extraírem os meios materiais necessários às suas necessidades, produzirem e reproduzirem as condições materiais de sua existência social" (Godelier, 1981, p. 169). Em um sistema produtivo, é o modo material de produção que define a divisão técnica do trabalho e, assim, absorve e organiza um conjunto de especialidades, de ocupações ou classes profissionais, que emergem e fenecem no ritmo das inovações tecnológicas e das reestruturações produtivas. Aqui, porém, o conceito de classe adquire um sentido preciso e táctil, sendo justo afirmar que, 
sob a égide do Fordismo, um torneiro-mecânico fazia parte de uma classe ocupacional especializada, corporificava emblematicamente a classe operária no auge de sua configuração histórica e, ainda, tanto lá como no regime atual de acumulação flexível (Harvey, 1992), é um representante típico da classe explorada no modo capitalista de produção. A cada nível de análise, de maior ou menor abstração, uma sentença.

No seu desenvolvimento, o capitalismo provocou uma contínua transformação da sua base técnica, mediante enorme impulsão das forças produtivas. Criando sua base própria, renovando-a segundo suas necessidades, o capitalismo realiza o que mais importa a um modo de produção: instaura o processo que vem a repor a sua própria realidade, reproduzindo-a historicamente. Por isso, formas econômicas desprovidas da capacidade de reconstituir-se não remeteriam ao modo de produção como unidade de análise, sob pena de retirar dessa categoria, como diz Shanin (1980, p. 65), "seus insights analíticos mais importantes". É o caso da economia familiar camponesa, ou da produção simples de mercadoria, às quais correspondem relações sociais de produção peculiares e, assim, classes específicas. A questão, nesse caso, consistiria em identificar que relações elas mantêm entre si, no interior dessas formas, e quais elos diretos ou indiretos possuem com o mecanismo de exploração próprio do modo de produção dominante.

O par exploradores/explorados desdobra-se à medida que focalizamos as configurações históricas de cada tempo e lugar, surgindo então subcategorias cujo ordenamento não deve perder de vista o critério inicial: o regime de exploração e sua estrutura dinâmica, no interior das relações sociais de produção dominantes e secundárias. Isso, conforme Wright (2015), podemos chamar de estrutura de classes.

Essa estrutura nuclear é suficiente para contrastar o modo de produção capitalista a outros, como o feudal, mas não para comparar estruturas de classe de sociedades capitalistas ou para examinar e localizar trajetórias sociais que não são diretamente afetadas pela estrutura básica das classes, caso notório das classes médias e das pessoas não vinculadas ao trabalho remunerado. Mantendo-se o mesmo princípio básico ordenador, pode-se chegar tanto a 
classes relativamente independentes quanto a posições contraditórias, em que coexistem propriedades e relações com a condição de explorados e de exploradores (especialistas e gerentes de firmas, por exemplo). Obtém-se assim um conjunto ordenado de posições de classe, mais ou menos elástico conforme os fins da análise, mas que ainda assim não se refere aos indivíduos empíricos ou às suas semelhanças ou diferenças aparentes, mas a situações teóricas com as quais sejam identificáveis, interpretando-se os seus traços significativos a partir de uma estrutura de relações latentes (Wright 2015, p. 147-149).

A elaboração de modelos complexos responde ao fato de que inúmeras formas secundárias podem surgir e desaparecer durante a vigência de um modo de produção. Existem margens de liberdade entre esses níveis de organização das práticas sociais e econômicas, sendo a economia capitalista, em verdade, pródiga em exemplos. A questão está em saber como o capitalismo atua ao fundo da cena, como tais formas existem e perduram, submetendo-se cada vez mais ou, pelo contrário, reduzindo sua vulnerabilidade ao modo de produção. Ou, ainda, como tais formas podem encetar movimentos de alargamento do seu próprio campo e da sua lógica interna a partir de seu lugar subalterno ou periférico, subtraindo-se em alguma medida ao controle do capital.

Para isso, é necessário saber se tais formas são típicas ou atípicas em relação ao modo de produção vigente. A questão conduz a uma terceira categoria, implícita nos textos de Marx, decorrente de sua preocupação em distinguir a aparência da estrutura interna de toda relação social. A estrutura nuclear de um modo de produção, seu caráter distintivo, repousa no conjunto de propriedades de que se reveste o processo de apropriação da natureza, nas relações mútuas que nele se engendram entre os indivíduos, de acordo com sua posição diante das condições e dos resultados dos diversos processos de trabalho e segundo as funções que desempenham. Tal estrutura está determinada pelas relações sociais de produção correspondentes, por uma forma social de produção mediante a qual é extorquido o trabalho do produtor direto. 
Cada modo de produção é, então, caracterizado por uma forma social de produção específica. Nas sociedades tribais primitivas, com base nas relações de parentesco, que ordenavam a apropriação do território, elemento chave para garantir os meios de subsistência; no feudalismo, pela imposição das obrigações servis, exercida pelos senhores da terra sobre quem nela trabalhava; no capitalismo, pelas relações assalariadas entre os vendedores da força-de-trabalho e os detentores dos meios de produção. Mais do que um contrato jurídico, o vínculo salarial materializa o mecanismo que permite a apropriação do trabalho excedente no interior do processo produtivo. As características anunciadas antes como típicas do capitalismo são, portanto, as mesmas que constituem a forma social de produção assalariada que lhe é peculiar e indispensável.

É em relação a essa forma que as posições sociais em uma estrutura de classe capitalista guardarão maior ou menor distância. Um consultor freelance, ao assinar um contrato de prestação de serviços contínuos nas instalações e nas condições de trabalho de uma empresa capitalista, ainda que mantenha sua independência jurídica formal, anda várias casas para o centro da estrutura de classes, enquanto um catador de materiais recicláveis que interpõe a sua cooperativa autogestionária na intermediação com seus clientes, postados um degrau acima na cadeia industrial da reciclagem, se afasta. Uma vantagem da estrutura de classes como dispositivo analítico é o fato de ser expansível, o que permite focalizar as classes em diferentes níveis, do mais teórico e abstrato ao mais empírico e concreto, sem perder de vista o seu princípio ordenador, assente nas relações de exploração. Supera-se, com isso, a suposta contradição entre classes teóricas e classes reais e transita-se da polarização basilar entre explorados e exploradores para as demais classes e frações de classe que se constituem em cada variante e em cada estágio de desenvolvimento do modo de produção. O enfoque das classes varia, assim, "segundo os interesses que presidem a análise em cada caso" (Santos, 1982, p. 14). Pode-se articular uma visão inicialmente dicotômica com uma perspectiva gradualista e mesmo um esquema "funcional", que relaciona as classes 
com as relações de propriedade e as fontes de renda, conforme sugere Santos (1982, p. 12-14).

A respeito da estrutura de classes própria do capitalismo contemporâneo, Wright propõe um modelo estendido, a partir de três classes fundamentais (capitalistas, trabalhadores e pequenos burgueses ${ }^{8}$ ), chegando então a seis classes: capitalistas, gerentes especializados, gerentes não especializados, pequenos burgueses, trabalhadores especialistas e trabalhadores sem qualificação (Wright, 2015, p. 147). Combinando algumas posições ou identificando categorias intermediárias, sempre com base em critérios relacionados à oposição fundamental entre proprietários e não proprietários dos meios de produção, o esquema é desdobrável sucessivamente, contanto que os critérios complementares de distinção se mostrem relevantes.

Empregando critérios compatíveis, Haddad identifica quatro classes na sociedade "superindustrial": 1) a classe dominante, dos proprietários do capital, dos funcionários do capital (alta gerência) e dos proprietários fundiários; 2) "a classe dos agentes sociais inovadores, portadores do conhecimento científico-tecnológico aplicado à produção", que constituem uma nova classe típica da formação social capitalista contemporânea; 3) a classe dos trabalhadores assalariados, ligados à produção de bens materiais ou imateriais, da qual ficam excluídos os funcionários públicos e os empregados domésticos, ambos trabalhadores "improdutivos" (por não venderem sua força de trabalho ao capital) e externos à produção, mas na qual se incluem os "trabalhadores de escritório" (que executam tarefas comerciais ou financeiras a serviço do capital), sem simplesmente ficarem situados na "nova classe média" ou na "classe de serviços"; 4) a "não-classe" dos trabalhadores, um conjunto heteróclito em que desponta o lumpemproletariado, à margem do sistema de exploração (Haddad, 2015, p. 101 et passim).

Nessas análises, as classes fundamentais transparecem na figura das classes diretamente associadas à forma social típica do modo de produção

${ }^{8}$ Esses últimos, nem exploradores, nem explorados, "possuem e usam os meios de produção sem contratar outras pessoas" (Wright, 2015, p. 140). 
vigente, conforme seu grau e forma de desenvolvimento. Outras classes são associáveis às primeiras, em decorrência das relações de subsunção existentes. Um terceiro nível de análise corresponde à estrutura de classes de sociedades singulares, concretas. Além de discernir as particularidades das classes sociais já identificadas nas etapas precedentes, é esperado que novas classes ou frações de classe se perfilem, em decorrência da primazia de certas relações econômicas e da sua expansão ou retraimento, dado o quadro geral das relações sociais e o complexo processo histórico de emergência e evolução das classes reais. Mantendo-se a espinha dorsal da estrutura de classes, mas acrescentando-Ihe novos critérios relacionados à totalidade social em tela, chega-se a uma estratificação social coerente com aqueles pressupostos, que assim revelam sua força e seus raios de abrangência naquele contexto específico. Pode-se, então, proceder a uma estratificação rural senhorial ou a uma estratificação urbana industrial, entre outras.

Convém, por fim, lembrar que a importância das classes sempre dependerá da relevância que se atribuir às relações sociais de exploração. Sem isso, as classes terão um papel secundário, acessório, talvez, diante das questões em análise. Portanto, as classes não explicam tudo e nem sempre explicam o que se deseja esclarecer das realidades sociais. Entretanto, se há clivagens sociais instituídas por e instituintes de relações de exploração, a análise da sociedade do ponto de vista das classes torna-se fundamental.

\section{Considerações finais}

O arcabouço teórico-conceitual assim proposto pretende evidenciar a possibilidade e a relevância de um tratamento classista das sociedades, sejam contemporâneas ou passadas, sem se ver comprometido pelas críticas e objeções levantadas quanto ao anacronismo, reducionismo e teleologismo imanente das teorias de classe, em particular em referência ao legado marxista. No entanto, conduzido até aqui, dito arcabouço não cerca todos as questões sociológicas suscitadas pela problemática das 
classes. Seria, com certeza, pretencioso fazê-lo num único texto. Por conseguinte, inevitavelmente restam aspectos em aberto, a exemplo dos vínculos entre classes, representações e condutas, como já assinalado ao final da primeira seção, supra. Marx não deu conta da complexa articulação entre economia, cultura e política porque lhe faltava uma teoria da subjetividade (Guimarães, 1999) e da passagem da classe à ação de classe. Para adentrar esse terreno, não é necessário abandonar as classes, mas sim acrescentar às classes uma teoria da formação de preferências e da mobilização social. Abordar esses desdobramentos, indicativamente, é o propósito dessas considerações finais.

A deficiência do marxismo em não dispor de uma teoria da subjetividade e da formação de laços de solidariedade social, é reiterada pela literatura (Bertoncelo, 2009, p. 33). Isso levou à conclusão de que as lutas econômicas conduziriam fatalmente a um despertar da consciência, em seguida à confrontação política e, por fim, a lutas revolucionárias. No lugar de antecipar ou pressupor tal desenlace, seria preciso ter em mãos instrumentos que expliquem os mecanismos pelos quais indivíduos, partilhando a mesma posição de classe, expressam seus presumíveis interesses de classe formando coletividades de ação. Seria preciso dar conta dos fatores que estimulam ou inibem tal tomada de consciência (Guimarães, 1991, p. 54) e induzem à mobilização social. Que pistas poderíamos seguir para avançar nessas matérias? Propomos duas vias.

Em primeiro lugar, nos termos de uma abordagem que relacione as condições materiais de vida, em sua função constituinte da vida cotidiana, a um dado modo de ver e a um conjunto de predisposições a agir. Ganharia centralidade aqui o conceito de éthos de posição ${ }^{9}$ (Gaiger, 1997), análogo ao conceito bourdesiano de habitus, evocando a natureza estruturada e transacional da cultura incorporada pelos integrantes de uma dada

${ }^{9}$ A existência de um conjunto de referências de sentido primordiais, enraizadas na história pessoal e estruturantes da cultura incorporada de cada indivíduo, constituiu o objeto de atenção de autores que, procurando teorizar sobre o processo de produção e reprodução cultural, formularam o conceito de éthos de posição (Remy; Voyé; Servais, 1978; Lalive D’Epinay et al., 1984). 
classe. ${ }^{10}$ Nessa ótica, as classes sociais não incorporam nem explicam todos os condicionantes que intervêm nas formas de agir de indivíduos e coletividades, mesmo no campo econômico; elas permitem dar conta de aspectos fundamentais, mas específicos, pois se referem primordialmente às relações de exploração. Por isso, a influência exercida pela classe se conjuga com influências de outras ordens, sofre a concorrência dessas na estruturação das representações sobre o mundo e das preferências no plano da ação.

Como demonstrou o próprio Marx quanto às correlações de classe na Alemanha e na França, em conjunturas do séc. XIX, as classes criam um campo disposicional, engendram uma sensibilidade específica que se traduz em valorações e em prioridades diante do mundo, a partir das quais se estabelecem uma visão das coisas e, conforme as circunstâncias, uma inclinação a determinadas estratégias de ação. Essas predisposições formam um sistema sociocultural latente à medida que se sedimentem ao longo do tempo. Condições objetivas e subjetivas precisam perdurar e adquirir alguma coerência para que influenciem similarmente os indivíduos em seus modos de pensar, de situar-se e de agir. Homogeneidade, estabilidade e longevidade são propriedades necessárias das condições de vida relacionadas em algum grau significativo à classe para que engendrem formas de consciência coletiva e de identidade, para evocar noções usuais no tratamento desses temas.

Atendidos tais requisitos, ditas condições sociais - de classe redundam em vivências e experiências similares; essas, por sua vez, produzem tendencialmente uma convergência entre modos e estilos de vida. Criam-se processos nem sempre conscientes de reconhecimento e diferenciação, de aprovação e rejeição, de adesão e repulsa; por consequência, de aproximação e de distanciamento social. Para cada

10 Tomando distância de usos correntes do conceito de habitus que enfatizam sua função reprodutora das representações e comportamentos, o enfoque pelo éthos deixa sobressair seu caráter adaptativo: ele é susceptível de estimular uma renovação das práticas, cuja incidência sobre as referências culturais não descarta rupturas das predisposições já incorporadas. 
pessoa ou coletividade, semelhanças e afinidades se revelam menos nas preferências conscientes do que na partilha de um senso prático. Como insistia Bourdieu, isso na medida em que o desempenho em toda ordem social, mais do que conhecimentos explícitos adquiridos para esse fim, requer saberes implícitos, "solidários de um éthos, isto é, de uma 'sabedoria' que não é constituída e unificada como tal", mas que permite a cada indivíduo "agir de maneira razoável e com chances de êxito no interior da sua própria sociedade" (Bourdieu, 1963, p. 26). No éthos encontramos então os vínculos entre identidade e projeto, entre razão e valor, entre concepção de mundo e ação sobre o mundo.

O peso específico da classe na definição do éthos de posição correspondente varia com a estrutura de classes e com a trajetória das classes em foco. Determinações classistas de primeira ordem, quando se examina um modo de produção ou uma forma social de produção, podem ficar ao fundo da cena quando as atenções se centram em uma dada sociedade ou conjuntura concreta, cabendo lembrar novamente os escritos de Marx sobre as Revoluções de 1848. Conflitos de natureza classista podem ganhar contornos adicionais acentuados em função de outros fatores, conferindo destaque a lutas nos campos cultural e simbólico.

Em segundo lugar, o efeito das predisposições incorporadas sobre a mobilização das classes conduz a um conjunto adicional de considerações e categorias de análise, às quais apenas aludiremos. Para tratar dessas questões, o ponto de partida deveria ser uma teoria da solidariedade social, dentro da qual se enquadre a solidariedade de classe - precisamente uma das lacunas dos desenvolvimentos marxistas centrados na luta de classes. Há várias formas e âmbitos de manifestação da solidariedade familiar ou comunitária, filantrópica ou estatal (Gaiger, 2016, p. 88-134) - sendo o éthos de posição um propulsor ou, pelo contrário, um elemento inibidor de umas e outras. Entendê-lo requer superar o tom utilitarista corrente em teorias sobre a ação coletiva, que findam em explicá-la por motivações e posturas oportunistas, sem as devidas ponderações. Caberia então acentuar o papel decisivo dos vínculos sociais na formação de laços 
de solidariedade (Gaiger, 2016), segundo uma perspectiva sociológica relacional (Bajoit, 2015) e, a partir daí, examinar o grau de propensão das experiências de classe a forjar predisposições vinculantes.

Desse ponto de vista, pode-se dizer que, sob o capitalismo, as classes penam para manter ou irradiar interesses comuns em âmbitos não econômicos. Com a expansão da sociedade de mercado, cada vez mais dependemos da renda auferida nesse sistema de intercâmbio de mercadorias, dentre elas a que provém do trabalho, instituído em moldes competitivos e individualistas como mercado de trabalho. Essa supremacia do econômico, terreno da exploração e da conformação das classes, no entanto, produz efeitos contraditórios sobre a solidariedade de classe, uma vez que a esfera econômica se torna independente e passa a sobrepor-se às lógicas sociais, adquirindo força decisiva na conformação dos grupos de interesse. As classes trabalhadoras são compelidas, então, a lutar por questões como salário e condições de trabalho, enquanto ocorre uma desintegração dos vínculos sociais, o que redunda em óbices à formação de elos duráveis de solidariedade, economicamente desinteressados.

O economicismo das classes, que motivou objeções à abordagem marxista, não depende propriamente delas ou de uma tendência universal dos agrupamentos humanos, mas se explica em nossa época por uma circunstância histórica peculiar, na qual descuidar-se dos interesses econômicos finda por comprometer todos os demais. Se as pautas econômicas mobilizam as classes, também as cingem a esse âmbito, em detrimentos de solidariedades mais amplas e abrangentes, capazes de romper o círculo de ferro utilitarista de nossa época.

Luiz Inácio Gaiger é Doutor em Sociologia e Professor do Programa de Pós-graduação em Ciências Sociais da Unisinos. $₫$ gaiger@unisinos.br 


\section{Referências}

1. BAJOIT, Guy. La maison du sociologue. Louvain-la-Neuve: L'Harmattan, 2015.

2. BERTONCELO, Edison. O espaço das classes sociais no Brasil. Tempo Social, São Paulo, v. 28, n. 2, p. 73-104, 2016. https://doi.org/10.11606/0103-2070. ts.2016.110534

3. BERTONCELO, Edison. As classes na teoria sociológica contemporânea. Boletim Informativo e Bibliográfico de Ciências Sociais, São Paulo, n. 67, p. 25-49, 2009.

4. BOITO Jr., Armando; BERRINGER, Tatiana. Brasil: classes sociais, neodesenvolvimentismo e política externa nos governos Lula e Dilma. Revista de Sociologia Política, Curitiba, v. 21, n. 47, p. 31-38, 2013. https://doi.org/10.1590/ $\underline{\mathrm{S} 0104-44782013000300004}$

5. BOTTOMORE, Thomas (Ed.). Dicionário do pensamento marxista. Rio de Janeiro: Jorge Zahar, 1988.

6. BOURDIEU, Pierre. Razões práticas. Sobre a teoria da ação. Campinas: Papirus, 1996.

7. BOURDIEU, Pierre. La société traditionnelle. Attitude à l'égard du temps et conduite économique. Sociologie du Travail, n. 1, p. 24-44, 1963.

8. DOIMO, Ana. A vez e a voz do popular. Movimentos sociais e participação política no Brasil pós-70. Rio de Janeiro: Relume-Dumará/ANPOCS, 1995.

9. DOWBOR, Ladislau. A era do capital improdutivo. São Paulo: Autonomia Literária, 2017.

10. DURAND-SEBAG, Joyce. Stratification et classe sociales. In: DURAND, Jean-Pierre; WEIL, Robert (Eds.). Sociologie Contemporaine. Paris: Vigot, 1989. p. 257-274.

11. FERRAZ, Sérgio. Voto e classe: notas sobre alguns estudos recentes. Opinião Pública, v. 15, n. 2, p. 451-477, 2009. http://dx.doi.org/10.1590/S0104$\underline{62762009000200007}$

12. GAIGER, Luiz. Ethos de posição e vida cotidiana. Estudos Leopoldenses, v. 33, n. 151, p. 69-94, 1997.

13. GAIGER, Luiz. A economia solidária diante do modo de produção capitalista. Caderno CRH, v. 39, p. 181-211, 2003.

14. GAIGER, Luiz. A descoberta dos vínculos sociais. Os fundamentos da solidariedade. São Leopoldo: Ed. Unisinos, 2016.

15. GIANNOTTI, José. Notas sobre a categoria "modo de produção" para uso e abuso dos sociólogos. Estudos CEBRAP, n. 17, p. 161-168, 1976.

16. GODELIER, Maurice. D'un mode de production à l'autre : théorie de la transition. Recherches Sociologiques, v. 12, n. 2, p. 161-93, 1981. 
17. GORENDER, Jacob. Marxismo sem utopia. São Paulo: Ática, 1999.

18. GORENDER, Jacob. O escravismo colonial. 2. ed. São Paulo: Ática, 1978.

19. GUIMARÃES, Antônio. Classes sociais. In: MICELI, Sérgio (Org.). O que ler na ciência social brasileira. São Paulo: Sumaré, p. 13-54, 1999. (v. 2).

20. GUIMARÃES, Antônio. Classes, interesses e exploração: comentários a um debate anglo-americano. Boletim Informativo e Bibliográfico de Ciências Sociais, n. 31, p. 49-66, 1991.

21. GUIMARÃES, Sônia. Faz sentido falar em classes sociais? Cadernos de Sociologia (Número Especial), n. 4, p. 85-92, 1993.

22. HADDAD, Fernando. Trabalho e classes sociais. Tempo Social, v. 9, n. 2, p. 97-124, 1997. https://doi.org/10.1590/ts.v9i2.86692

23. HARVEY, David. A condição pós-moderna. São Paulo: Loyola, 1992.

24. LALIVE d'ÉPINAY, Christian et al. Vieillesses. Situations, itinéraires et modes de vie des personnes âgées aujourd'hui. Saint-Saphorin: Georgi, 1984.

25. LAREAU, Annette. A desigualdade invisível: o papel da classe social na criação dos filhos em famílias negras e brancas. Educação em Revista, n. 46, p. 13-82, 2007. http://dx.doi.org/10.1590/S0102-46982007000200002

26. MARX, Karl. O capital (Crítica da economia política). Rio de Janeiro: Civilização Brasileira, 1974 [1890-1894]. (Livro 3, v. 6).

27. MOSCOVICI, Serge. Psicologia das minorias ativas. Petrópolis: Vozes, 2011.

28. OLIVEIRA, Francisco. O elo perdido: classe e identidade de classe. São Paulo: Brasiliense, 1987.

29. PRZEWORSKI, Adam. From proletariat into a class: The process of class formation from Karl Kaustki's "The Class Struggle" to recent controversies. Politics and Society, v. 7, n. 4, p. 343-371, 1977.

30. REMY, Jean; VOYE, Liliane; SERVAIS, Émile. Produire ou reproduire ? Une sociologie de la vie quotidienne. Bruxelas: Vie Ouvrière, 1978.

31. SADER, Eder. Quando novos personagens entram em cena - experiências e lutas dos trabalhadores da Grande São Paulo, 1970-1980. São Paulo: Paz e Terra, 1988.

32. SADER, Eder; PAOLI, Maria. Sobre "classes populares" no pensamento sociológico brasileiro. In: CARDOSO, Ruth (Org.). A aventura antropológica. Teoria e pesquisa. São Paulo: Paz e Terra, 1986. p. 39-67.

33. SANTOS, Boaventura de S. Para uma sociologia das ausências e uma sociologia das emergências. Revista Crítica de Ciências Sociais, n. 63, p. 237-280, 2002.

34. SANTOS, Theotonio. O conceito de classes sociais. Petrópolis: Vozes, 1982. 
35. SASSEN, Saskia. Expulsions: Brutality and Complexity in the Global Economy. Harvard: Harvard University Press, 2014.

36. SHANIN, Theodor. A definição de camponês: conceituações e desconceituações; o velho e o novo numa discussão marxista. Estudos CEBRAP, n. 26, p. 44-80, 1980.

37. SCHERER-WARREN, Ilse; KRISCHKE, Paulo (Orgs.). Uma revolução no cotidiana? Os movimentos sociais na América Latina. São Paulo: Brasiliense, 1987.

38. SILVEIRA, Paulo; DORAY, Bertrand (Orgs.). Elementos para uma teoria marxista da subjetividade. São Paulo: Editora Revista dos Tribunais, 1989.

39. THERBORN, Göran. Desigualdade global: o retorno da classe. Diálogo Global, v. 2, n. 1, p. 3-5, 2011.

40. VIANA, Nildo. A teoria das classes sociais em Karl Marx. Lisboa: Editora Chiado, 2018.

41. WRIGHT, Eric. Comprender las clases sociales. Madrid: Ediciones Akal (e-book), 2018.

42. WRIGHT, Eric. Análise de classes. Revista Brasileira de Ciência Política, n. 17, p. 121-163, 2015. https://doi.org/10.1590/0103-335220151705 
